\title{
An Analysis of $A$ Long Walk to Freedom from the Perspective of Transitivity System
}

\author{
Jiangping Zhou ${ }^{1,2}$ \\ ${ }^{1}$ China West Normal University, Nanchong, China \\ ${ }^{2}$ Peking University, Beijing, China \\ Email: zhoujp@pku.edu.cn
}

How to cite this paper: Zhou, J. P. (2020). An Analysis of $A$ Long Walk to Freedom from the Perspective of Transitivity System. Open Journal of Modern Linguistics, 10, 195-202.

https://doi.org/10.4236/ojml.2020.103012

Received: May 14, 2020

Accepted: May 29, 2020

Published: June 2, 2020

Copyright (c) 2020 by author(s) and Scientific Research Publishing Inc. This work is licensed under the Creative Commons Attribution International License (CC BY 4.0).

http://creativecommons.org/licenses/by/4.0/

\begin{abstract}
The application of Systemic Functional Linguistic theories into text analysis is not new, and so is the transitivity system. This paper combines the qualitative and quantitative research methodologies to elucidate how Mandela, chapter 115 of $A$ Long Walk to Freedom, deploys the elements of transitivity system to expound his ideas to his compatriots and align them together with him to fight for their freedom. The findings show that he mainly incorporates material processes and relational processes and deliberately uses the passive voice to invoke his fellow countrymen to fulfill the role of "actors".
\end{abstract}

\section{Keywords}

Meaning of Freedom, Transitivity System, Systemic Functional Linguistics

\section{Introduction}

A Long Walk to Freedom is an autobiography of Nelson Mandela, (Mandela, 2008), who, as the most prestigious prisoner in the world, experienced twenty-seven years of hardship in jail in South Africa. His four years of striving for freedom for his countryman out of jail won him the president in South Africa and was also spoken highly of his lofty virtue by the world. Eventually, South Africa, under Mandela's leadership, turned to be democratic from a country of long-term barbarity and atrocious apartheid. The material for analysis in this paper, meaning of freedom, is extracted from the last genre of chapter 115, an autobiographical recount.

Martin and Rose (2007) adopted the same chapter as materials, including meaning of freedom, to help them establish different systems in systemic functional linguistics in their book working with discourse. As a matter of 
fact, the material extracted is of great value not only in servicing for the development of systemic functional theories, but also of great significance in itself, that is, how Mandela realizes his meaning potentials. In this paper, the procedures of realizing the meaning potential are presented from the perspective of transitivity system. Based on this viewpoint, two questions, thus, are raised: 1) How the subcategories of transitivity system are deployed through meaning of freedom? 2) In what way Mandela constructs his autobiographical recount with the employment of transitivity system, especially the employment of specific processes?

\section{Theoretical Framework}

In traditional grammar, transitivity system usually centers on the properties of verbs, i.e. whether an object or objects could be positioned directly after the verb, thus, we have transitive verb if could be followed directly, and intransitive verb if could not (Zhang, 2017). The domain of transitivity from the traditional sense has been expanded by Halliday (1994) and Halliday \& Matthiessen (2004), to include not only the verbal groups, but also the nominal groups and some of other groups in grammatical units. Halliday terms these groups as "participant, process, and circumstance" respectively in semantic domain. From the point of view of transitivity, a clause can then be interpreted as a lexicogrammatical resource for construing our experience of the flow of events (Halliday \& Matthiessen, 1999). According to Halliday \& Matthiessen (1999), the process is very significant in configuration of a figure, a figure of doing, sensing, being and the fusion of either of the two. Each figure is composed of a process unfolding through time and one or more participants explicitly associated around the process; additionally, there may be circumstances of various types realized by grammatical categories of adverbial groups or prepositional phrases, positioning, to some extent, freely in the clause (Halliday \& Matthiessen, 2004; 2014). The process of each figure is an obligatory element, and if it is left out in the clause, there must be one way or another to recover it from the context. The same principle applies to the element of participant, which either causes the activity to happen or becomes the target or product of the action. The circumstance provides a harmonious environment for the participant and the process to exist meaningfully.

Process of the transitivity system is further classified by Halliday and Matthiessen (2004) into material, mental, relational, behavioural, verbal and existential processes. Material process construes the human outer experience of the creation of an activity, for instance, have not taken in We have not taken the final step of our journey, but the first step on a longer and even more difficult road. Mental process is to construe the inner world of an emotion, for example, know in I know that this is not the case. Besides, a third type of process, which shows the association of one segment of experience with another one, is a relational process, subcategorized as either classifying or identifying. That was my mission is an identifying, while $I$ am not free is an attributive relational process clause. 
The former three are the main types of processes. However, the latter three types can also find their realizations at the three boundaries. Behavioural process, which externalizes the inner experience or outperforms the processes of consciousness, is on the borderline of material and mental process. Verbal process, like saying or meaning, reports what was said, is on the borderline of mental and relational process. Existential process, on the borderline of relational and material process, demonstrates the existence of the phenomenon of all kinds (Halliday \& Matthiessen, 2014). In the following analysis of Mandela's Meaning of freedom within the framework of these process types, we are expounding the procedures and approach how Mandela represents his meaning of freedom to his readers.

\section{Methodology}

\subsection{Selection of Materials}

We have selected the last genre of chapter 115, meaning of freedom, as our text resource, and the motivation of this part is not only due to its significance in the whole book and the wide spreading among its readers, but also phases in each stage are clearly deployed, which is very beneficial for us to capture the progressions of Mandela's ideas of freedom armed with transitivity system.

\subsection{Data Collection}

Firstly, the total words, verbal groups and clauses in the text are counted by the automatic syntactic analyzer system ( $\mathrm{Lu}, 2010 ; \mathrm{Lu} \& \mathrm{Ai}, 2015)$ : total words $(\mathrm{N}=$ $724)$, verbal groups $(\mathrm{N}=104)$, clauses $(\mathrm{N}=80)$. Non-finite clauses, such as infinitive and present participle, functioning as embedded or modifying elements are excluded from the transitive analysis, because they, together with their head, constitute the nominal groups. Therefore, the valid verbal groups for process analysis accounts for $\mathrm{N}=94$. Besides that, processes in transitivity system and their corresponding participants and circumstantial components are annotated manually. Thirdly, total occurrence of each component in participants, process types and circumstances are numbered and collected by a computer. Finally, these raw numerals are converted into standard percentage for the convenience of analysis.

\subsection{Results}

Components within each specific element are very unevenly deployed. The results are shown in Table 1. However, material process (49\%) dominates the other process types, followed by relational process (28\%) and mental process (11\%) subsequently. The other three process types, (behavioural, verbal and existential process), all together only makes up 12\%, which are shown in Figure 1. The findings of process distribution are in accordance with what the earlier researchers have discovered (e.g., Halliday \& Matthiessen, 2014; Halliday \& Matthiessen, 1999).

Because of the high preferences of the three process types, their corresponding 
sub-types of participants will be automatically higher than the other sub-types. Actor/goal of material process accounts for $38 \%$, and if it is summed with the proportion of occurrence of relational participantial sub-types $36 \%$, the two types of participantial components take the lion's share among the six kinds of participants, see Figure 2.

Pertaining to the distribution of circumstances, what Mandela favors most is the use of manner and location to expand his clauses. According to Figure 3, manners of the circumstance account for $39 \%$ of the total and locations of the circumstance take the share of $25 \%$, while the other kinds of circumstance only share one third or so.

Table 1. Frequency of elements in transitivity system.

\begin{tabular}{|c|c|c|c|c|c|c|c|c|}
\hline \multicolumn{3}{|c|}{ Participant } & \multicolumn{3}{|c|}{ Process } & \multicolumn{3}{|c|}{ Circumstance } \\
\hline & raw $N$ & $\%$ & & raw $\mathrm{N}$ & $\%$ & & raw $\mathrm{N}$ & $\%$ \\
\hline actor & 20 & 14 & \multirow{3}{*}{ material } & \multirow{3}{*}{46} & \multirow{3}{*}{49} & extent & 4 & 14 \\
\hline & & & & & & & & \\
\hline goal & 35 & 24 & & & & location & 7 & 25 \\
\hline behaver & 4 & 3 & \multirow{3}{*}{ behavioural } & \multirow{3}{*}{7} & \multirow{3}{*}{7} & manner & 11 & 39 \\
\hline & & & & & & & & \\
\hline behaviour & 11 & 8 & & & & cause & 1 & 4 \\
\hline senser & 9 & 6 & \multirow{3}{*}{ mental } & \multirow{3}{*}{10} & \multirow{3}{*}{11} & contingency & 0 & 0 \\
\hline & & & & & & & & \\
\hline phenomenon & 8 & 6 & & & & accompaniment & 4 & 14 \\
\hline \multirow[t]{2}{*}{ sayer } & 2 & 1 & \multirow{3}{*}{ verbal } & \multirow{3}{*}{3} & \multirow{3}{*}{3} & role & 1 & 4 \\
\hline & & & & & & & & \\
\hline verbiage & 2 & 1 & & & & matter & 0 & 0 \\
\hline \multirow[t]{2}{*}{ token } & 14 & 10 & \multirow{3}{*}{ relational:iden } & \multirow{3}{*}{15} & \multirow{3}{*}{16} & angle & 0 & 0 \\
\hline & & & & & & & & \\
\hline value & 15 & 10 & & & & & & \\
\hline carrier & 11 & 8 & & & & & & \\
\hline & & & relational:attr & 11 & 12 & & & \\
\hline attribute & 11 & 8 & & & & & & \\
\hline existent & 2 & 1 & existential & 2 & 2 & & & \\
\hline
\end{tabular}

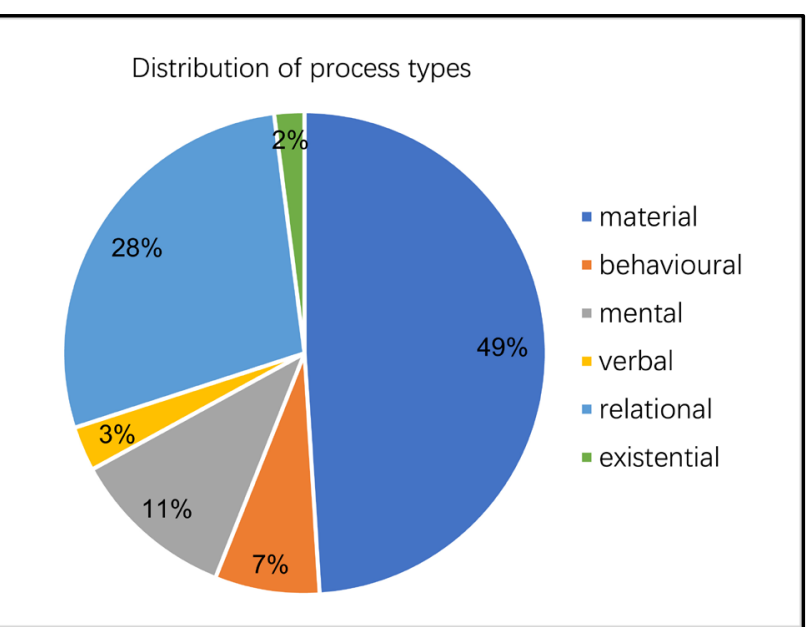

Figure 1. Distribution of process types. 


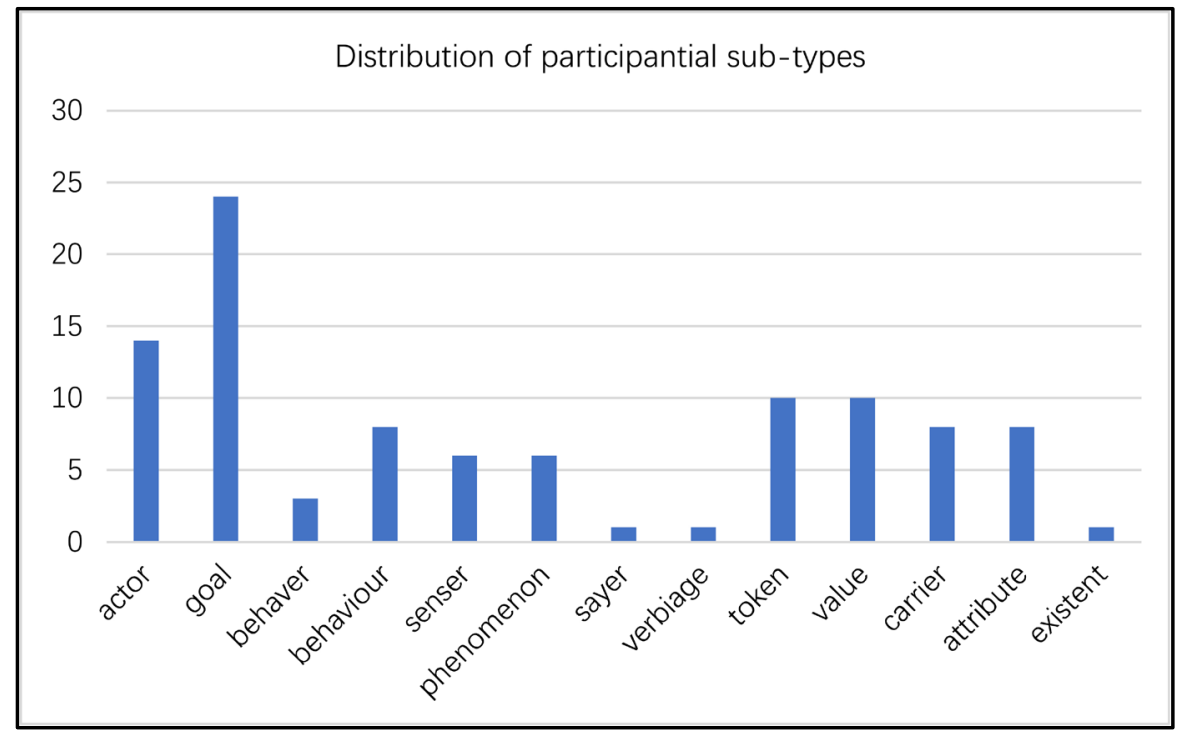

Figure 2. Distribution of participantial sub-types.

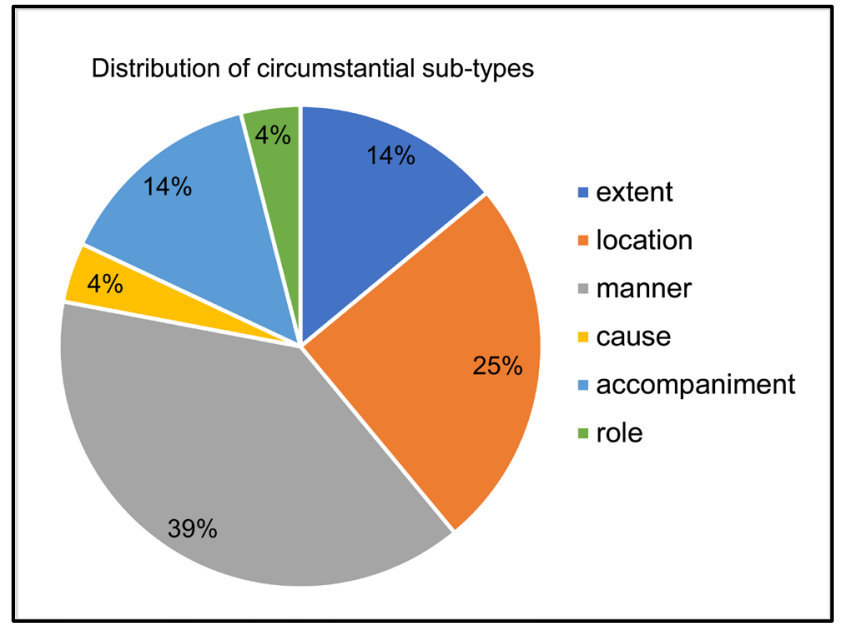

Figure 3. Distribution of circumstantial sub-types.

\section{Analysis}

After carefully analyzing these preferred elements, i.e. preferences of material, mental and relational process types and their corresponding participants (surprisingly, actors and behavers are absent in a great proportion), predilections of location and manner in circumstantial elements, we find that these elements are more easily associated with expressing Mandela's ideas and align his readers, especially his country people.

\subsection{High Proportion of Absent Actors and Behavers}

The high percentage of the use of material processes, in principle, will cause the high proportion of their corresponding participants to be adopted. However, the factual clauses are not the case. A huge number of actors (35\%) and goals (25\%) are missing compared with the occurrence of material processes (49\%). For ex- 
ample:

(1) Free to run in the fields near my mother's hut, free to swim in the clear stream that ran through my village, free to roast mealies under the stars and ride the broad backs of slow-moving bulls.

(2) The oppressor must be liberated just as surely as the oppressed.

(3) He is locked behind the bars of prejudice and narrow-mindedness.

(4) I dare not linger, for my long walk is not yet ended.

Because "run" and "swim" in example (1) and "linger" in example (4) are all intransitive verbs, it is not necessary for the action to be accommodated with a goal grammatically. However, Mandela employs circumstantial elements in the fields near my mother's hut or a circumstantial element with a embedded clause in the clear stream that ran through my village to enhance the main clause and thus make the meaning complete. The above four clauses have some in common that activities are either realized by non-finite clauses or by passive clauses, which are grammatically not obligatory in demanding an actor to initiate or actualize the action. For Mandela, the lacking of actors in his utterances will make his words more objective and all the people oppressed in his country be involved, that is to say, all the oppressed are welcome to join his community to fight for the freedom of the country and also the freedom of their own.

\subsection{Preferences of Material and Relational Process Types}

Figures in Table 1 show that material process (49\%) in Meaning of Freedom dominates the other types of processes. Grammatical means that realize these material processes are varied, which include not only the passive and active voices in finite clauses, but infinitive in non-finite clauses, for instance, example (5)and (6) are realized in activity and passivity respectively; and example (7) are realized in infinitivity.

(5) I have tried not to falter; I have made missteps along the way.

(6) I was not troubled by the laws of man or God.

(7)..., but to live in a way that respects and enhances the freedom of others.

The overwhelmingly occurred material processes establish a more coherent and intrinsic relation between the sequence of events and participants, concerning with the actors' specific action or the actors' goal. Mandela calls for his compatriots to take action immediately for the freedom of the whole nation by showing that he himself is already involved in the physical action.

Relational process (28\%) is also a preferred type for Mandela. It can be further classified into attributive clause and identifying clause, which is exemplified by Example (8) and example (9) respectively.

(8) I am not truly free if I am taking away someone else's freedom, just as surely as I am not free when my freedom is taken from me.

(9) The chains on any one of my people were the chains on all of them, the chains on all of my people were the chains on me.

The relational processes and their related participants are, in most cases, asso- 
ciated together negatively, either morphologically or semantically. In other words, Mandela intently adopted relational processes to negatively express what he wants to, and this type of process can, in the shortest distance, pull the identified and the identifying together and affiliate the attributes to the carriers more directly. Specifically, the rhetorical approach of repetition (e.g.: several times of repetition of $I$ am not free) is harmoniously and perfectly combined with relational process, by so doing, Mandela can carry out his invocation of his fellow countrymen to join in his group with a strong emotional feeling and claims the action to be fulfilled urgently.

\subsection{Predilections of Location and Manner in Circumstance}

Clauses enhanced by place and time demonstrate clearly where these sequences of events happened and when these activities occur. These two measures are very important in framing a story, and this autobiographical recount is of no exception, either. Examples (10) and (11) employed different ways of location realized by prepositional phrases.

(10) Free to run in the fields near my mother's hut, free to swim in the clear stream that ran through my village.

(11) When I walked out of prison, that was my mission, to liberate the oppressed and the oppressor both.

Besides the circumstantial element of location, manner is also employed with a very high frequency by Mandela, because it is an important factor to elicit in what way the event occurs. e.g.: the prepositional phrase in a way that respects and enhances the freedom of others in example (12) expounds the way of being free to live.

(12) For to be free is not merely to cast off one's chains, but to live in a way that respects and enhances the freedom of others.

Therefore, Mandela, as the other authors, incorporates the circumstantial elements of location and manner to unfold his work, more specifically, the three critical means in answering where, when and how in a story.

\section{Conclusion}

Through manual annotation of the specific elements of participants, processes and circumstances, and then statistic analysis, we find that the components of each element are very unevenly deployed in Mandela's Meaning of Freedom. The preference of material and relational processes demonstrate that he is not just telling his fellow countrymen that they should fight all together for their freedom, but he has already been in the process of the long journey (material process), together with showing that their present status of living is not free at all (relational process). Passive voice is employed for him to deliberately leave out the actors, for the purpose of aligning his countrymen as the actors themselves to fight for the freedom with him. Nevertheless, the application of transitivity system is not enough to expose Mandela explicit purposes, let alone his implicit 
ideas underneath these superficial text meanings. We hope some other SFL theories, such as textual meaning and grammatical metaphor, can be incorporated into the analysis of Meaning of Freedom, or even the whole book of $A$ Long Walk to Freedom.

\section{Acknowledgements}

This paper is funded by China West Normal University, (Project No. 11A009).

\section{Conflicts of Interest}

The author declares no conflicts of interest regarding the publication of this paper.

\section{References}

Halliday, M. A. K. (1994). An Introduction to Functional Grammar. London: Edward Arnold.

Halliday, M. A. K., \& Matthiessen, C. M. I. M. (1999). Construing Experience through Language: A Language-Based Approach to Cognition. London: Continuum.

Halliday, M. A. K., \& Matthiessen, C. M. I. M. (2004). An Introduction to Functional Grammar(3rd ed.). London: Edward Arnold.

Halliday, M. A. K., \& Matthiessen, C. M. I. M. (2014). An Introduction to Functional Grammar (4th ed.). London/New York: Routledge.

https://doi.org/10.4324/9780203783771

Lu, X. F. (2010). Automatic Analysis of Syntactic Complexity in Second Language Writing. International Journal of Corpus Linguistics, 15, 474-496. https://doi.org/10.1075/ijcl.15.4.02lu

Lu, X. F., \& Ai, H. Y. (2015). Syntactic Complexity in College-Level English Writing: Differences among Writers with Diverse L1 Backgrounds. Journal of Second Language Writing, 29, 16-27. https://doi.org/10.1016/j.jslw.2015.06.003

Mandela, N. (2008). A Long Walk to Freedom. New York: Little, Brown and Company.

Martin, J. R., \& Rose, D. (2007). Working with Discourse: Meaning beyond the Clause. London: Continuum.

Zhang, Z. B. (2017). A New English Grammar Course Book. Shanghai: Shanghai Foreign Language Education Press. 